\title{
The Impact of Medicare's Prospective Payment System (PPS) On Hospitals and Physicians
}

\author{
Charles P. Swisher, B.S.
}

\section{DOI: http://dx.doi.org/10.5915/17-1-12748}

The passage of the Tax Equity and Fiscal Responsibility Act of 1982 (TEFRA) and the Social Security Amendments of I983 introduced major changes in the way hospitals are reimbursed by the Medicare program. Payment to hospitals for medically necessary inpatient services will no longer be made on a reasonable cost basis. Hospitals are now at "risk" for the cost of services that are provided.

The Medicare Prospective Payment Service (PPS) legislation provides for the study of physician payments on the basis of Diagnosis Related Groups (DRGs). The Health Care Financing Administration (HCFA) has until October 1, 1985, to complete the study of physician DRG payments and present their recommendations to Congress. Physicians could face the challenge of different incentives when providing impatient services to Medicare patients as early as October 1, 1986.

The new Medicare payment system has the potential of creating both opportunity and conflict between hospitals and physicians as we operate under new payment incentives. The experience to date has been cooperation and increased understanding of the problems and limitations facing hospitals. The challenge to hospitals and physicians in the future will be the delivery of highquality care in a cost-effective manner.

\section{The Competitive Environment}

The passage of the Tax Equity and Fiscal Responsibility Act of 1982 (TEFRA) and the Social Security Amendments of 1983 introduced major changes in the way hospitals are reimbursed by the Medicare program. Payments to hospitals for medically necessary inpatient services are no longer being made on a reasonable cost basis. Hospitals are now at "risk" for the cost of services that are provided. Medicare's prospective payment system (PPS) is based on 23 major diagnostic categories (MDCs) which are further broken down into 468 diagnosis-related groups (DRGs) which have a clinical significance. Payments to hospitals will represent a $50 / 50$ blending of hospital-specific and federal rates effective for reporting periods beginning October 1, 1984. However, by October 1, 1986, Medicare DRG rates will be $100 \%$ federal rates, with the only adjustment being made for area wage indices.

The changes in the Medicare payment system are reflective of the other changes taking place in the health care environment. Limited financial resources coupled with increasing demand for services creates an untenable condition for preservation of the status quo. The increase in the percentage of the population over age 65 is increasing significantly. It is estimated that the number of aged persons will double from the present 26 million to 52 million by the year 2020 . The cost pressures created by the sheer numbers of individuals requiring health care services and qualifying for Medicare benefits is phenomenal. We can anticipate additional government cutbacks as evidenced by the July 3, 1984, notice of proposed rulemaking appearing in the Federal Register. The proposed rule limits the amount of increase allowed for FY 1984 through arbitrary reductions in the market basket index and DRG weights.

Senior Vice-President

Missouri Hospital Association

Jefferson City, Missouri
The reduction in DRG price increases will be overshadowed by the establishment of Peer Review Organizations (PROs) which will have quotas to meet in terms of reduced utilization. The Missouri Patient Care Review Foundation (Missouri's PRO) signed a two-year contract with HCFA effective August 1, 1984 , that required them to reduce admissions statewide by 65,328 , or about $10 \%$ each year.

We are seeing evidence of the competitive forces at work in our environment with the development of health maintenance organizations (HMOs), preferred provider organizations (PPOs) and exclusive provider organizations (EPOs). In Missouri, the state Medicaid program has initiated lock-in programs for the 5,000 general relief recipients in Kansas City and St. Louis. Thirty thousand Medicaid AFDC beneficiaries in Kansas City will be enrolled in a capitation program in Kansas City by October 1, 1984. Enrollment of the 55,000 Medicaid AFDC recipients in St. Louis in a similar capitation program is expected in 1985. The Kansas City Blue Cross plan developed a PPO last year that has enrolled over 20,000 subscribers to date and the St. Louis Blue Cross plan is developing a similar plan. Other PPOs have been developed or are under development in both Kansas City and St. Louis.

HMOs are having an impact on the health care industry and their hospitalization rates are 40 percent below those for the fee-for-service system. A recent Rand Corporation study has shown preferential enrollment to be a minor factor when evaluating HMO experience. The study showed that two thirds of the preventive business to HMOs are for well-child care and gynecologic examinations and that there is no discernable difference among outcomes (morbidity and mortality) between the HMO-enrolled groups and the general population. It is also interesting to note that less than $10 \%$ of the Blue Cross HMO enrollees changed to non-HMO coverage at their option date, indicating general satisfaction with their care. 
The impending surplus of physicians will have a significant impact on our environment. The current number of 450,000 physicians nationwide is estimated to increase to 600,000 within 10 years. Intensified competition and movement by physicians to protect their practices and incomes can be anticipated with the likely outcome being more physicians on salary, increased participation in competitive prepaid plans and larger numbers locating in rural areas. Problems are also likely to continue in terms of the mix of physician specialties and distribution of physicians in rural and inner-city areas.

\section{Changing Incentives and Strategies}

The jury is still out on marketplace health care and whether or not competition will be effective in the long run. However, there is no question that different financial incentives have changed providers' behavior. Evidence can be found in the preliminary reports published by the Health Care Financing Administration (HCFA) which shows that the total number of Medicare admissions have decreased slightly and the average length of stay has also decreased. The result is fewer total inpatient days and lower occupancy rates. In 1983, Missouri hospitals' costs rose only 9.8 percent, the lowest increase since Medicare was enacted in 1965. The experience so far in 1984 appears to be even lower, with the increase in total hospital expenditures averaging $9.4 \%$. This experience reverses a 17 -year trend. Outpatient visits and the use of non-hospital services continue to increase as alternatives to acute care are sought by providers and patients.

Acute inpatient care is the core service for most hospitals. Directly connected services are emergency care, home health care, adult day care, extended-hour physician services, wellness centers, substance abuse treatment, nursing home care and primary care. Hospitals seek to strengthen their competitive advantage by offering these connected services as well as filling in other gaps such as psychiatric care, rehabilitation, dental care, pharmacy services, medical products, ambulatory surgery, birthing centers, nutrition services, etc. A "circle of care" concept will probably emerge with hospitals and physicians directing movement within the circle. The purpose behind the development of a comprehensive circle of care is to keep people in a captive system and to expand/protect market share.

These strategies may require diversification, networking and restructuring, but are likely to retain these common threads: health-centered orientation, market segmentation and maintenance, reliance upon acute care as their core business, growth strategies, risk ventures and protection against outside or competing forces.

Individual hospital responses in development of strategies will differ. Many hospitals are viewing participation and multi-hospital systems (MHS) as one way of obtaining security and addressing the demands and challenges of the future. Much like competition and marketplace incentives, the future of MHSs is still waiting for the jury to come in. MHSs are organized differently with varying financial structures and interhospital relationships. Despite these differences and the intense competition that exists among MHSs, they are likely to increase in visibility and numbers throughout the rest of this decade.

\section{Implications for Medical Staff}

The circle of care concept mentioned previously (aligning alternative services and expanding the hospital's financial base) will result in many potential joint ventures with physicians in what might be termed a kind of "economic bonding." In the short term, conflicts between hospitals and physicians are likely to occur as hospitals expand into alternative services and competition for available dollars becomes intense. However, the projected surplus of physicians will lead to inter-physician conflicts. The combined impact of the changes in the payment system and the increasing number of physicians will threaten the traditional practices and levels of personal income for many physicians. These changes will speed the development of joint ventures and creation of salaried positions for physicians in hospitals as physicians look for security and stability in a changing and threatening environment.

The Missouri Hospital Association staff analysis and projections of our future health care environment have identified the following assumptions which may be of interest to you:

(a) It is likely that Congress will enact legislation to require Medicare to pay physicians on a prospective payment basis for hospial inpatients by October 1, 1986, probably on a DRG-related system.

(b) Private marketplace forces will create more and create pressure for HMOs, PPOs, EPOs and other prepaid systems for hospital and physician care.

(c) Physicians and hospitals will respond to the marketplace environment by creating various types of competing, delivery and financing systems, some of which will cover limited services while others will incorporate a circle of care ranging from preventive care to acute care to home care and other levels of service.

(d) Physicians and hospitals will provide fee-forservice care but will move toward participation and market segmentation plans; that is, more people will be cared for in closed systems (capitation or otherwise).

(e) Hospitals and physicians will become bonded together through numerous joint ventures and arrangements which protect them in the competitive marketplace.

(f) Physicians will be more involved in the health care strategic planning process, including the hospitals' individual plans. As a result, physicians will tend to become monogamous, rather than maintaining membership on multiple hospital medical staffs.

(g) Medical staff functions will become more defined, particularly in urban areas and multiinstitutional communities. It is likely that 
specialists will play the predominant role in hospital care, with primary care physicians directing out of hospital care.

In conclusion, I maintain that the biggest challenge facing hospitals and physicians in the future will be the delivery of high quality medical care in a cost-effective manner. Financing of care for the medically indigent must also be addressed under competitive plans. In all likelihood, this means the development of minimum benefit levels and acceptance of multiple levels of care for people in our society. The incentives under Medicare PPS have the potential to create substantial changes in the health care delivery system if payments are adequate. However, as mentioned previously, Congress has already taken action to arbitrarily reduce Medicare DRG payments. Such action is likely to jeopardize the foundation upon which Medicare PPS was agreed to by the hospital industry - that is, that payments would be adequate and fair. 